\title{
Hemangioblastomatosis in a patient with von Hippel-Lindau disease
}

\author{
M. C. J. Hanse $\cdot$ A. Vincent $\cdot$ M. J. van den Bent
}

Received: 29 October 2006/ Accepted: 14 December 2006/ Published online: 26 January 2007

(C) Springer Science+Business Media B.V. 2007

Keywords Von Hippel-Lindau disease . Hemangioblastoma

\section{Case presentation}

A woman developed a cerebellar hemangioblastoma in 1991 at the age of 17 and von Hippel-Lindau disease was diagnosed. She underwent five craniotomies for recurrent hemangioblastoma. In 2001 she had a laminectomy for an intramedullar hemangioblastoma at C2-C3 level. In 2004 a renal cell carcinoma was found and a partial nephrectomy was performed. A few weeks after her last craniotomy in July 2005 she developed progressive right hemisensory disturbances and sensory ataxia. Spinal MRI showed leptomeningeal contrast enhancement around the entire spinal cord (see Figure). The sensory ataxia progressed and she got tetraparesis, most severe proximally in

M. C. J. Hanse $(\bowtie) \cdot$ M. J. van den Bent

Neuro-oncology Unit, Daniel den Hoed Cancer Centre,

Erasmus University Medical Center,

PO Box 5201, 3008 AE Rotterdam,

The Netherlands

e-mail: monique.hanse@cze.nl

\section{A. Vincent}

Department of Neurosurgery,

Erasmus University Medical Center,

PO Box 2040, 3000 CA Rotterdam,

The Netherlands

\section{C. J. Hanse}

Department of Neurology,

Catharina Hospital,

PO Box 1350, 5602 ZA Eindhoven,

The Netherlands her arms, especially myotome C4. Although hemangioblastoma are not very radiosensitive, radiotherapy was started because of the rapid clinical deterioration. High-dose total neuraxis radiotherapy was considered to toxic. It was judged that most of her clinical complaints could be attributed to the cervical spine. Also the MRI showed the most severe lesions at the cervical region. Therefore she was treated from $\mathrm{C} 1$ to Th1 $(30 \times 1.8 \mathrm{~Gy})$ combined with dexamethasone $(2 \times 8 \mathrm{mg})$. During radiotherapy she developed also symptoms outside the radiotherapy field (thoracal radiculopathy).

As the main problem in VHL is uncontrolled angiogenesis by overexpressing VEGF and VEGF receptors, Thalidomide (400 mg, later $600 \mathrm{mg}$ ) was added. Thalidomide inhibits angiogenesis induced by VEGF [1]. Despite the treatment she developed a total tetraplegia and died 3 months after diagnosis as a result of respiratory failure.

This syndrome appears to result from delayed growth of subarachnoid tumor cells disseminated by surgery. Hemangioblastomatosis is also seen in hemangioblastoma patients without von Hippel-Lindau disease and it is thought that additional genes are likely to be the source of this malignant behaviour [2].

\section{References}

1. Piribauer M, Czech T, Dieckmann K et al. (2004) Stabilization of a progressive hemangioblastoma under treatment with thalidomide. J Neurooncol 66:295-299

2. Weil RJ, Vortmeyer AO, Zhuang Z et al. (2002) Clinical and molecular analysis of disseminated hemangioblastomatosis of the central nervous system in patients without von HippelLindau disease. J Neurosurg 96:775-787 


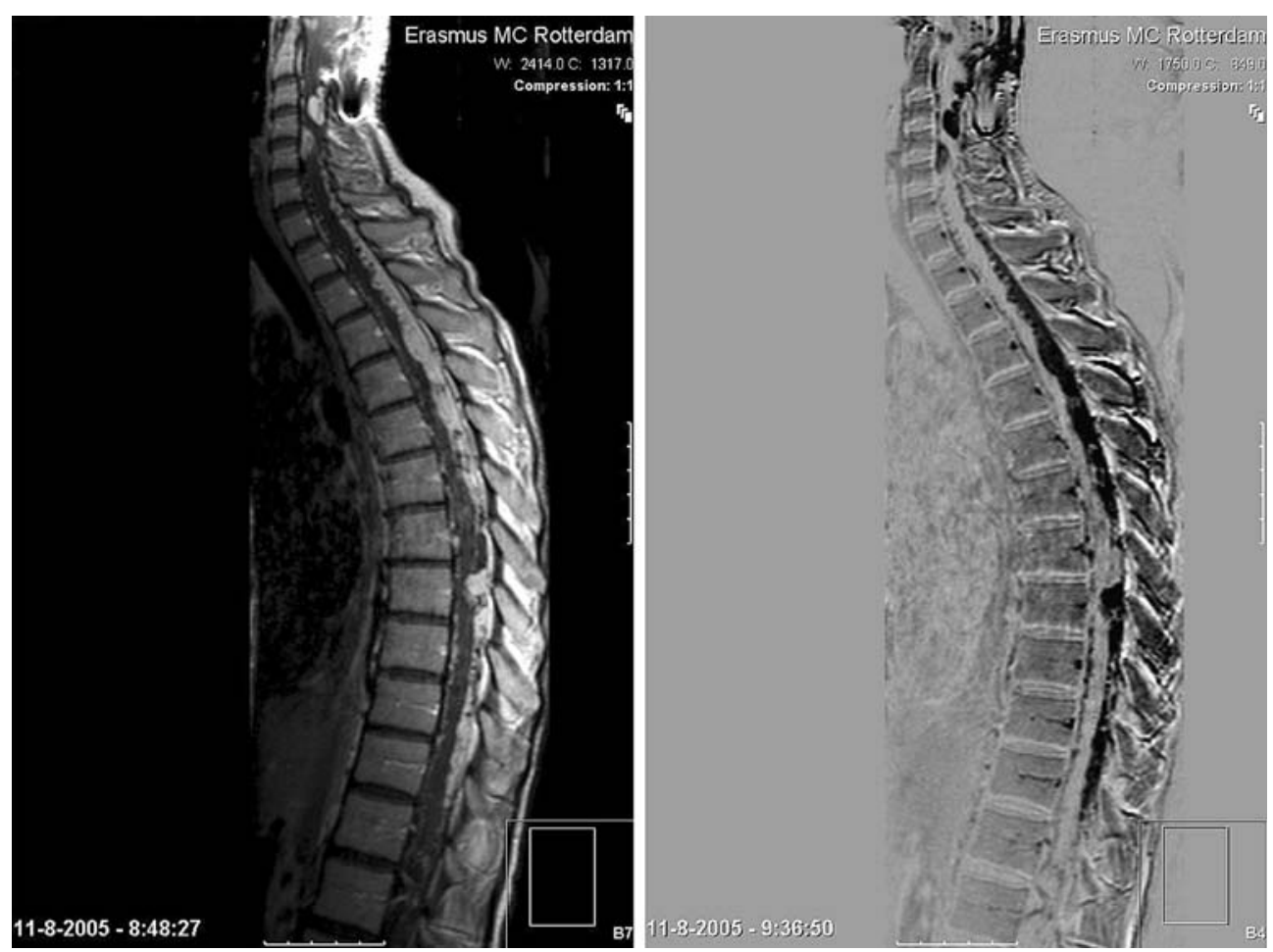

